Canadian Journal of Physics

Canadian

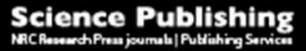

Revue canadienne de physique

\title{
Thermoluminescence and dosimetric characteristics study of quartz samples from Seyhan Dam Lake Terraces
}

\begin{tabular}{|r|l|}
\hline Journal: & Canadian Journal of Physics \\
\hline Manuscript ID & cjp-2017-0741.R1 \\
\hline Manuscript Type: & Article \\
\hline Date Submitted by the Author: & 21-Nov-2017 \\
\hline $\begin{array}{r}\text { Complete List of Authors: } \\
\text { Keyword: }\end{array}$ & $\begin{array}{l}\text { Yüksel, Mehmet; Çukurova University Arts-Sciences Faculty, Physics } \\
\text { Department }\end{array}$ \\
\hline $\begin{array}{r}\text { Is the invited manuscript for } \\
\text { consideration in a Special } \\
\text { Issue? : }\end{array}$ & 33rd International Physics Conference of Turkish Physical Society \\
\hline \multicolumn{2}{|r}{} \\
\hline
\end{tabular}

\section{SCHOLARONE ${ }^{\text {tw }}$}

Manuscripts 


\section{Thermoluminescence and dosimetric characteristics study of quartz samples from}

\section{Seyhan Dam Lake Terraces}

6

7

8
3

$4 \quad{ }^{1}$ Çukurova University, Arts-Sciences Faculty, Physics Department, 01330 Adana, Turkey.

\section{Mehmet Yüksel $^{1}$}

(n)

\begin{abstract}
In the present study, the soil samples of Seyhan Dam Lake Terraces were collected and then pure quartz samples were separated using some separation methods. The quartz samples were characterized using X-ray diffraction (XRD) and scanning electron microscopy-energy dispersive X-ray spectroscopy (SEM-EDX) methods. Thermoluminescence (TL) measurements were carried out using lexsyg smart TL/OSL reader with a constant heating rate of $5^{\circ} \mathrm{C} / \mathrm{s}$ from room temperature to $450^{\circ} \mathrm{C}$. Beta dose response of the samples were investigated in the dose range from 1 to $10 \mathrm{~Gy}$ and the linear dose response range was determined as 1-5 Gy. Computerized glow curve deconvolution (CGCD), peak shape (PS) and isothermal decay (ID) methods were used to determine activation energy (E), order of kinetics (b), and frequency factor (s) of the samples. Furthermore, in this study, minimum detectable dose (MDD) value of the quartz samples were also determined.
\end{abstract}

Keywords: Quartz, thermoluminescence, activation energy, CGCD, ID.

PACS: $78.60 . \mathrm{Kn}$, 87.66.Sq

\section{Introduction}

The phenomenon of luminescence is related to the interaction of radiation with mineral grains, by the activation of and subsequent trapping of electrons at defects within the mineral lattice[1]. Thermoluminescence (TL), a type of luminescence, is defined as the emission of light from a semiconductor or an insulator when it is heated, because of the previous absorption of energy from irradiation[2]. Many of the natural minerals, especially different quartz minerals, have TL properties and quartz based minerals are popular to study their TL characteristics due to radiation sensitivity, basic structure of glow curve, and simple thermal treatment procedure. TL from quartz is commonly used in retrospective dosimetry, in particular for the dating of archaeological materials and sediments from the Quaternary period[1]. Different quartz minerals may show different TL properties and when the irradiated quartz minerals are heated from room temperature (RT) to a higher temperature, glow 
curves from various forms of quartz exhibit great differences in shape[3-5]. Many investigations on quartz have been performed about its different properties [1, 6-11]. Some of the different studies about TL and OSL methods by using quartz samples are presented below:

A number of optical properties of a natural quartz that are related to the presence of electron traps having an optical depth of about $3 \mathrm{eV}$ below the conduction band were described by Huntley and et al. [12], the effects of annealing, heating rate and fading (after annealing at $800^{\circ} \mathrm{C}$ ) on the TL glow curves of natural quartz were investigated by Yüksel et al.[6], the use of TL method to distinguish between burned and unburned soil samples were investigated using quartz samples obtained from soil by Rengers et al. [13], the study of OSL dating of coarse-grain fluvial quartz using single-aliquot protocols on sediments was investigated by Fuchs and Lang [14], and in order to refine the OSL age of the last earthquake on the Dheshir fault in Central Iran, quartz samples were used by Fattahi et al. [15]. The aim of the present study is to characterize the quartz samples obtained from the soils of Seyhan Dam Lake Terraces using different methods. For this purpose, the method of separating quartz from soil, results of XRD, SEM-EDX, luminescence analyses, linear dose response range, minimum detectable dose (MDD) value and kinetic parameters (activation energy, frequency factor and order of kinetic) were presented.

\section{Material and Methods}

\subsection{Sample Preparation}

The soil samples were collected from Seyhan Dam Lake terraces in Adana and the sampling point location is $37^{\circ} 04^{\prime} 26.4^{\prime \prime} \mathrm{N} 35^{\circ} 20^{\prime} 43.0^{\prime \prime} \mathrm{E}$. The collected soil sample from these terraces is seen in Fig. 1. Collected samples contain a mixture of various materials such as quartz, feldspar, fluorite, organic and carbonate. Mixed soil samples were gently grinded in an agate mortar to obtain grain sizes in the range 90-140 $\mu \mathrm{m}$. In order to obtain pure quartz from soil samples, the following subsequent chemical processes were applied, respectively.

i) The grinded mixture was sieved as wet. (It enables simple separation of fractions) 
ii) The mixture was etched with hydrochloric acid $(\mathrm{HCl}, 10 \%)$ to eliminate corbonates that

iii) The mixture was etched with hydrogen peroxide $\left(\mathrm{H}_{2} \mathrm{O}_{2}, 30 \%\right)$ to eliminate organics (for 24 hours) and then it was washed with distilled water three times.

iv) The mixture was etched with hydrofluoric acid (HF, 38\%) to eliminate feldspars and to remove effect of alpha particles contribution to do total dose (for 1 hour) and then it was washed with distilled water three times.

v) The mixture was again etched with $\mathrm{HCl}(10 \%)$ to eliminate fluorites for 1 hour and then it was washed with distilled water three times.

vi) A magnet was used to remove the iron from samples and then the samples were washed with distilled water three times.

vii) The obtained powder samples were dried in the oven at $40^{\circ} \mathrm{C}$ for 24 hours.

viii) The powder samples were weighed $\left(\mathrm{m}_{1}=10.7, \mathrm{~m}_{2}=10.4, \mathrm{~m}_{3}=10.2 \mathrm{mg}\right)$ and three aliquots of each samples were mounted on stainless steel sample cups using silicon oil.

\section{Experimental Procedure}

The IRSL/OSL ratio test, X-ray diffraction (XRD), scanning electron microscopy-energy dispersive X-ray spectroscopy (SEM-EDX) and thermoluminescence (TL) methods were used for characterization of the obtained quartz samples. The XRD patterns of as-prepared samples were recorded on Rigaku SmartLab X-ray powder diffractometer with $\mathrm{Cu}-\mathrm{K}_{\alpha}=1.5406 \AA$ over the range $2 \theta=10-90^{\circ}$. The morphological studies of the samples were done by the field-emission scanning electron microscope (Zeiss Supra-55) images. Thermoluminescence (TL) measurements were carried out using an automatic lexsyg smart TL/OSL reader system. It has a standard bi-alkaline cathode UVVIS Hamamatsu photomultiplier tube (PMT) unit $(280-650 \mathrm{~nm})$ and attached to filter pack consisting of a Schott-BG 39-glass-3 mm; AHF-BrightLine HC 575/25-Interference-5 mm filter (TL $565 \mathrm{~nm}$ ).

Beta ( $\beta$ )-irradiation was performed using a $1.85 \mathrm{GBq}(50 \mathrm{mCi}){ }^{90} \mathrm{Sr} /{ }^{90} \mathrm{Y} \beta$-source (dose rate: 115 $\mathrm{mGy} / \mathrm{sec}$ ) with a maximum energy of $2.2 \mathrm{MeV}$. TL glow curve readouts were performed on a stainless 
84

85

86

87

88

89

90

91

92

steel disc at a linear heating rate of $5^{\circ} \mathrm{C} / \mathrm{s}$ up to $450^{\circ} \mathrm{C}$. The background was subtracted from the $\mathrm{TL}$ data belonging to each one.

\section{Results and Discussion}

\subsection{IRSL/OSL Ratio Test, XRD and SEM-EDX Analysis}

The absence of feldspars in the obtained quartz samples was proven by an IRSL/OSL ratio test. The samples were irradiated beta dose of $1 \mathrm{~Gy}$ using ${ }^{90} \mathrm{Sr} /{ }^{90} \mathrm{Y} \beta$-source and then first, blue light stimulation was carried out to achieve the measurements for $200 \mathrm{~s}$ at room temperature (RT). Secondly, infrared (IR) stimulation also was carried out in a similar way and decay curves of the samples were recorded (Fig. 2a). The IRSL/OSL ratio was calculated as 0.08 . Therefore, the samples do not contain feldspars. If quartz stimulates with IR light, it has either a weak or no signal. Fig. $2 b$ represents the XRD patterns of the samples and the XRD patterns of the obtained samples exhibit a set of sharp and welldefined diffraction peaks which are in good agreement with the pure quartz (The International Centre for Diffraction Data, ICDD, PDF Number: 01-085-1054).

Surface morphology, a plot of energy $(\mathrm{keV})$ of the emitted X-ray photons as a function of intensity provides energy dispersive X-ray spectroscopy (EDX) spectra and the elemental composition of the sample are seen in the Fig. 3. The elemental analysis results represent the amount of silicon (Si) and oxygen $(\mathrm{O})$ present in the sample. As seen in Fig. 3, obtained samples consist of 53.21\% Si and $46.79 \%$ O elements.

\subsection{TL Analyses}

For TL analyses, quartz samples were irradiated with a $\beta$-source $\sim 2$ Gy. Irradiated quartz samples were heated from RT up to $450^{\circ} \mathrm{C}$ with a heating rate $1^{\circ} \mathrm{C} / \mathrm{s}$ and then the $\mathrm{TL}$ glow curves were plotted (Fig. 4a). As seen in Fig. 4a, quartz samples have three TL glow peaks at 101,135 and $355^{\circ} \mathrm{C}$. Trap depths of the samples were calculated using TLanal software[16] for each peak and the three electron traps at 1.01, 1.04 and $1.62 \mathrm{eV}$ shown in Fig. 5b were confirmed from TL studies. 
111 TL dose response of the quartz samples were measured over the beta $(\beta)$ dose range from 1 Gy to 10

112 Gy and $\mathrm{TL}$ glow curves were recorded for $\mathrm{TL}$ glow peak at $101^{\circ} \mathrm{C}$. In order to determine the linear 113 dose range, the heights of the TL glow peaks were used and the linear dose curve was plotted in a log$114 \log$ scale (Fig. 5). As seen in Fig. 5, TL glow peak at $101^{\circ} \mathrm{C}$ has a linear dose range between 1 Gy and $1155 \mathrm{~Gy}$, and then it has sublinear dose range.

116 In the TL studies, determining the kinetic parameters, activation energy (E), order of kinetics (b), 117 frequency factor (s), are important to explain the luminescence characteristics of the materials. For this 118 reason, TL kinetic parameters of the quartz samples were determined using computerized glow curve 119 deconvolution (CGCD), peak shape (PS) and isothermal decay (ID) methods for the first peak at $120101^{\circ} \mathrm{C}$. The samples were irradiated with beta dose of 2 Gy and TL glow curves were recorded from 121 RT to $150^{\circ} \mathrm{C}$ to determine the TL kinetic parameters. However, TL glow curves were recorded after 122 pre-heating process at 85,95 and $105^{\circ} \mathrm{C}$ to determine the TL kinetic parameters for ID method.

123 TL glow curve of the samples were decomposed using TLanal software[16]. The accuracy of the 124 presented value is supportable with figure of merit (FOM) value and the FOM value is $1.65 \%$ for this 125 calculation. The obtained trap parameters were given in Table 1 . TL peak at $101^{\circ} \mathrm{C}$ has a first order 126 kinetic and the determined activation energies and the frequency factors of quartz samples using 127 CGCD, PS and ID methods, are $1.01 \pm 0.04 \mathrm{eV}$ and $1.71 \times 10^{13} \mathrm{~s}^{-1}, 0.98 \pm 0.05 \mathrm{eV}$ and $2.50 \times 10^{12} \mathrm{~s}^{-1}$ and $1.11 \pm 0.06 \mathrm{eV}$ and $3.90 \times 10^{12} \mathrm{~s}^{-1}$, respectively.

Furthermore, in this study, minimum detectable dose (MDD) value of the quartz samples were also determined for the first TL peak using following equation. In order to calculate the minimum detectable dose three aliquots of the quartz samples were used for background variation measurements and the TL reader was calibrated using the samples irradiated with 2, 3, and 5 Gy beta doses which were the linear dose response range (Fig. 5 and Fig. 6).

$$
D_{0}=\left(B^{*}+2 \sigma_{B}\right) F
$$

134 Where $\mathrm{B}^{*}$ is the mean TL background signal obtained from the samples, $\sigma_{B}$ is the standard deviation 135 of the mean background and F is the TL system calibration factor[17]. The MDD was found to be as $136 \quad 1.419 \pm 0.071 \mathrm{mGy}$. 


\section{Conclusion}

139 In this study, the quartz samples were obtained from the soil samples of Seyhan Dam Lake Terraces

140 using different chemical processes. First, the obtained quartz samples were characterized to understand whether they were quartz or not. The IRSL/OSL ratio test, the XRD patterns and SEM-EDX analyses showed that the samples were quartz and it consists of $\mathrm{Si}(53.21 \%)$ and $\mathrm{O}(46.79 \%)$ elements. XRD patterns of the samples are compatible with the ICDD PDF Number: 01-085-1054 $\left(\mathrm{SiO}_{2}\right)$. The TL characteristics of the quartz samples have been investigated under $\beta$-irradiation. The TL peaks of the samples were observed at around 101,135 , and $355^{\circ} \mathrm{C}$ and the energy-level diagram of the quartz samples were drawn for the three electron traps at $1.01,1.04$ and $1.62 \mathrm{eV}$. TL peak at $101^{\circ} \mathrm{C}$ were studied in details. Linear and sublinear dose response range of the samples were determined as 1-5 Gy and 6-10 Gy for TL peak at $101^{\circ} \mathrm{C}$, respectively. CGCD, PS and ID methods were used to determine $\mathrm{E}, \mathrm{b}$, and s parameters of the samples. The MDD value of the quartz samples for TL peak at $101^{\circ} \mathrm{C}$ was calculated and it was found as $1.419 \pm 0.071 \mathrm{mGy}$.

\section{References}

[1] F. Preusser, M.L. Chithambo, T. Gotte, M. Martini, K. Ramseyer, E.J. Sendezera, G.J. Susino, A.G. Wintle, Quartz as a natural luminescence dosimeter, Earth-Sci Rev, 97 (2009) 184-214. [2] V. Pagonis, G. Kitis, C. Furetta, Numerical and practical exercises in thermoluminescence, Springer Science \& Business Media2006.

157 [3] S.A. Petrov, I.K. Bailiff, The 110-Degrees-C TI Peak in Synthetic Quartz, Radiation Measurements, 15824 (1995) 519-523.

159 [4] W.F. Hornyak, R. Chen, A. Franklin, Thermoluminescence Characteristics of the 375-Degrees-C 160 Electron Trap in Quartz, Phys Rev B, 46 (1992) 8036-8049. [5] M. Topaksu, M. Yuksel, T. Dogan, N. Nur, R. Akkaya, Z. Yegingil, Y. Topak, Investigation of the characteristics of thermoluminescence glow curves of natural hydrothermal quartz from Hakkari area in Turkey, Physica B-Condensed Matter, 424 (2013) 27-31.

[6] M. Yuksel, T. Dogan, E. Unsal, Z.G. Portakal, S. Akca, Z. Yegingil, M. Topaksu, Thermoluminescence properties of annealed natural quartz after beta irradiation, Luminescence, 31 (2016) 1513-1518.

[7] M. Topaksu, T. Dogan, M. Yuksel, K. Kurt, Y. Topak, Z. Yegingil, Comparative study of the thermoluminescence properties of natural metamorphic quartz belonging to Turkey and Spain, Radiation Physics and Chemistry, 96 (2014) 223-228.

[8] T. Dogan, H. Toktamis, M. Yuksel, M. Topaksu, A.N. Yazici, Thermoluminescence glow curve analysis of natural onyx from Turkey, Applied Radiation and Isotopes, 96 (2015) 13-19.

[9] T. Chuenpee, O. Nishikawa, Y. Kon, K. Ninagawa, S. Toyoda, T. Ogata, T. Uchida, I. Takashima, Gamma radiation-induced thermoluminescence, trace element and paramagnetic defect of quartz from the Sambagawa metamorphic belt, Central Shikoku, Japan, Applied Radiation and Isotopes, 120 (2017) 30-39. 
Page 7 of 14

Canadian Journal of Physics

175

176

177

178

179

180

181

182

183

184

185

186

187

188

189

190

191

192

[10] W.J. Rink, K.D. Peeper, Quartz thermoluminescence in a storm deposit and a welded beach ridge, Quaternary Sci Rev, 20 (2001) 815-820.

[11] M. Martini, G. Spinolo, A. Vedda, Thermally Stimulated Luminescence of Thermally Grown SionFilms, Radiation Effects and Defects in Solids, 105 (1987) 107-116.

[12] D.J. Huntley, M.A. Short, K. Dunphy, Deep traps in quartz and their use for optical dating, Can. J. Phys., 74 (1996) 81-91.

[13] F.K. Renters, V. Pagonis, S.A. Mahan, Can thermoluminescence be used to determine soil heating from a wildfire?, Radiation Measurements, 107 (2017) 119-127.

[14] M. Fuchs, A. Lang, OSL dating of coarse-grain fluvial quartz using single-aliquot protocols on sediments from NE Peloponnese, Greece, Quaternary Sci Rev, 20 (2001) 783-787.

[15] M. Fattahi, H. Nazari, M.D. Bateman, B. Meyer, M. Sébrier, M. Talebian, K. Le Dortz, M. Foroutan, F. Ahmadi Givi, M. Ghorashi, Refining the OSL age of the last earthquake on the Dheshir fault, Central Iran, Quaternary Geochronology, 5 (2010) 286-292.

[16] K.S. Chung, H.S. Shoe, J.I. Lee, J.L. Kim, S.Y. Chang, A computer program for the deconvolution of thermoluminescence glow curves, Radiation Protection Dosimetry, 115 (2005) 343-349.

[17] C. Furetta, M. Prokic, R. Salmon, G. Kits, Dosimetric characterisation of a new production of MgB4O7:Dy,Na thermoluminescent material, Applied Radiation and Isotopes, 52 (2000) 243-250.

https://mc06.manuscriptcentral.com/cjp-pubs 


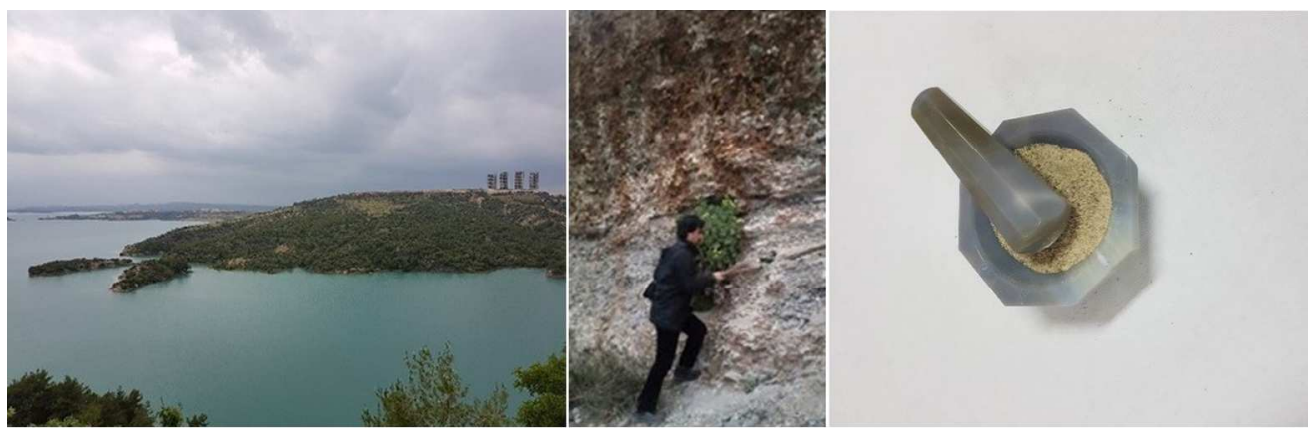

Figure 1. The collected soil sample of Seyhan Dam Lake terraces.

$535 \times 171 \mathrm{~mm}(72 \times 72$ DPI $)$ 

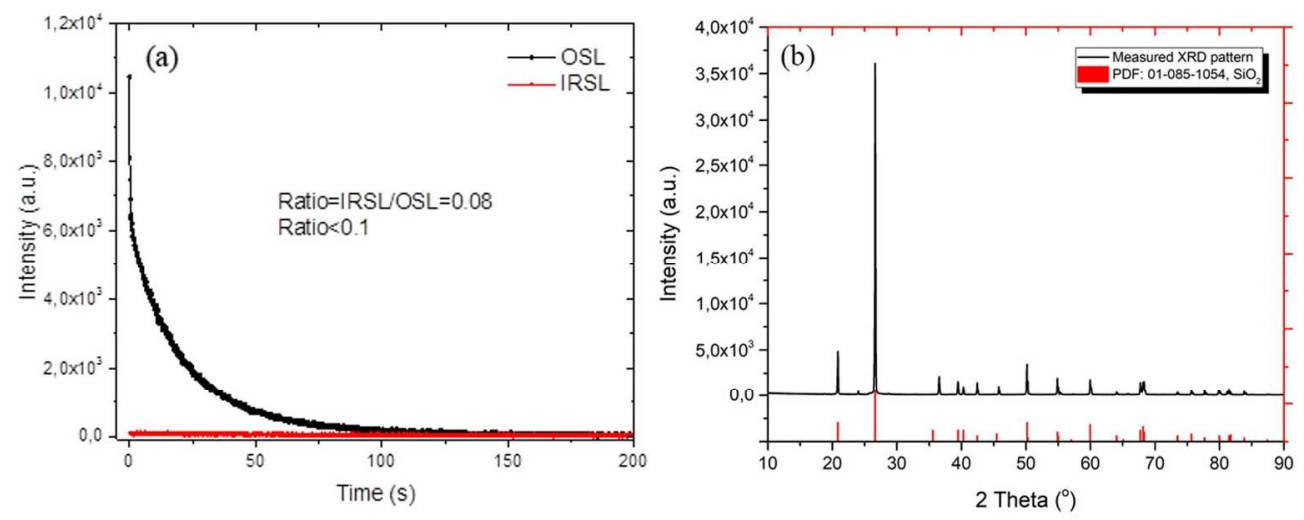

Figure 2. (a) The IRSL/OSL ratio test and (b) XRD pattern results for the obtained samples.

$519 \times 203 \mathrm{~mm}(96 \times 96 \mathrm{DPI})$ 


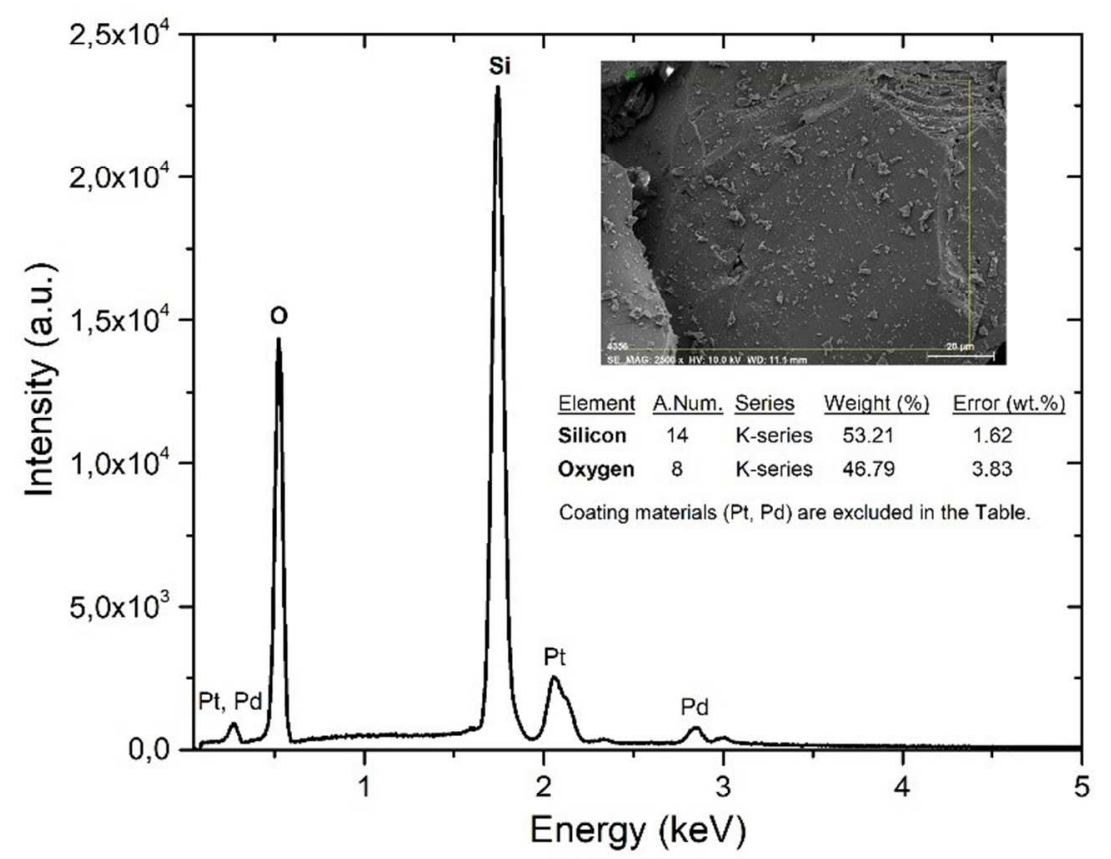

Figure 3. The SEM/EDX analysis results for the obtained samples. $110 \times 84 \mathrm{~mm}(220 \times 220$ DPI $)$ 

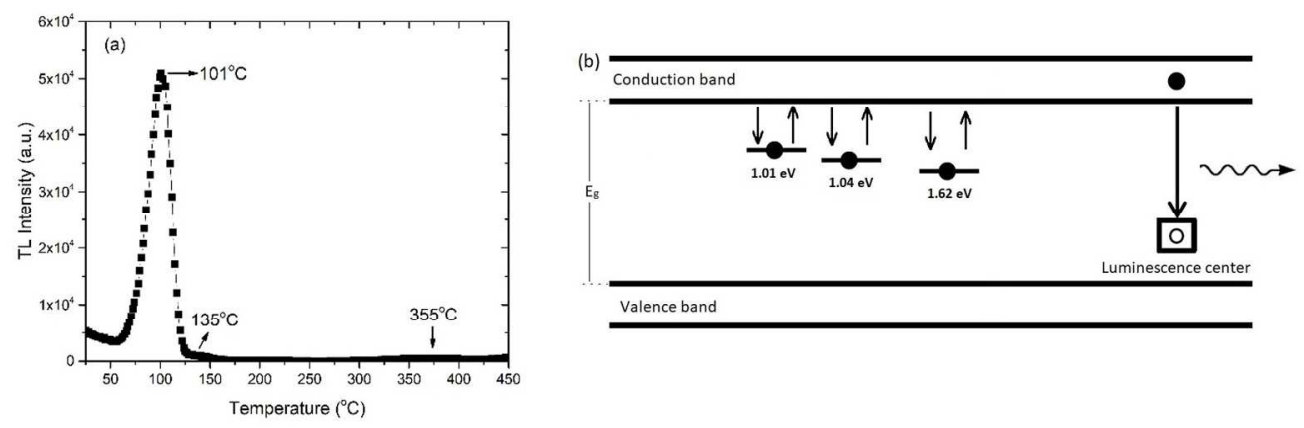

Figure 4. (a) TL glow curve and (b) energy-level diagram of the obtained quartz samples.

$558 \times 182 \mathrm{~mm}(96 \times 96 \mathrm{DPI})$ 


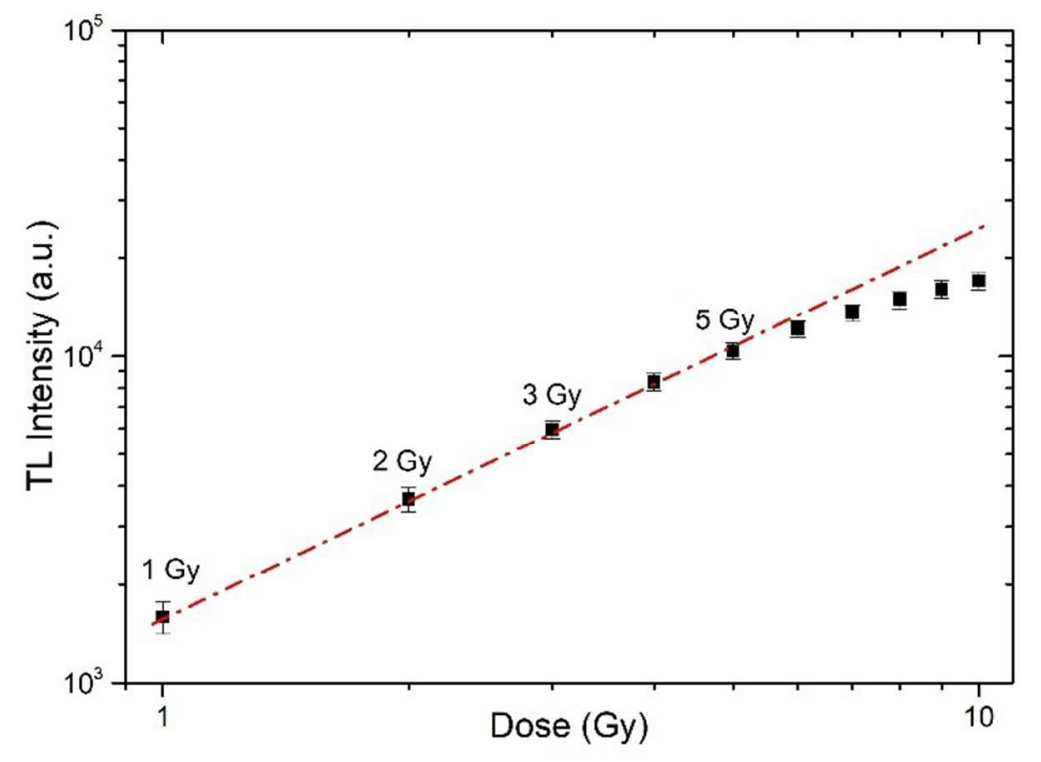

Figure 5. TL dose response of the obtained quartz samples for TL glow peak at $101^{\circ} \mathrm{C}$. $110 \times 77 \mathrm{~mm}(220 \times 220 \mathrm{DPI})$ 


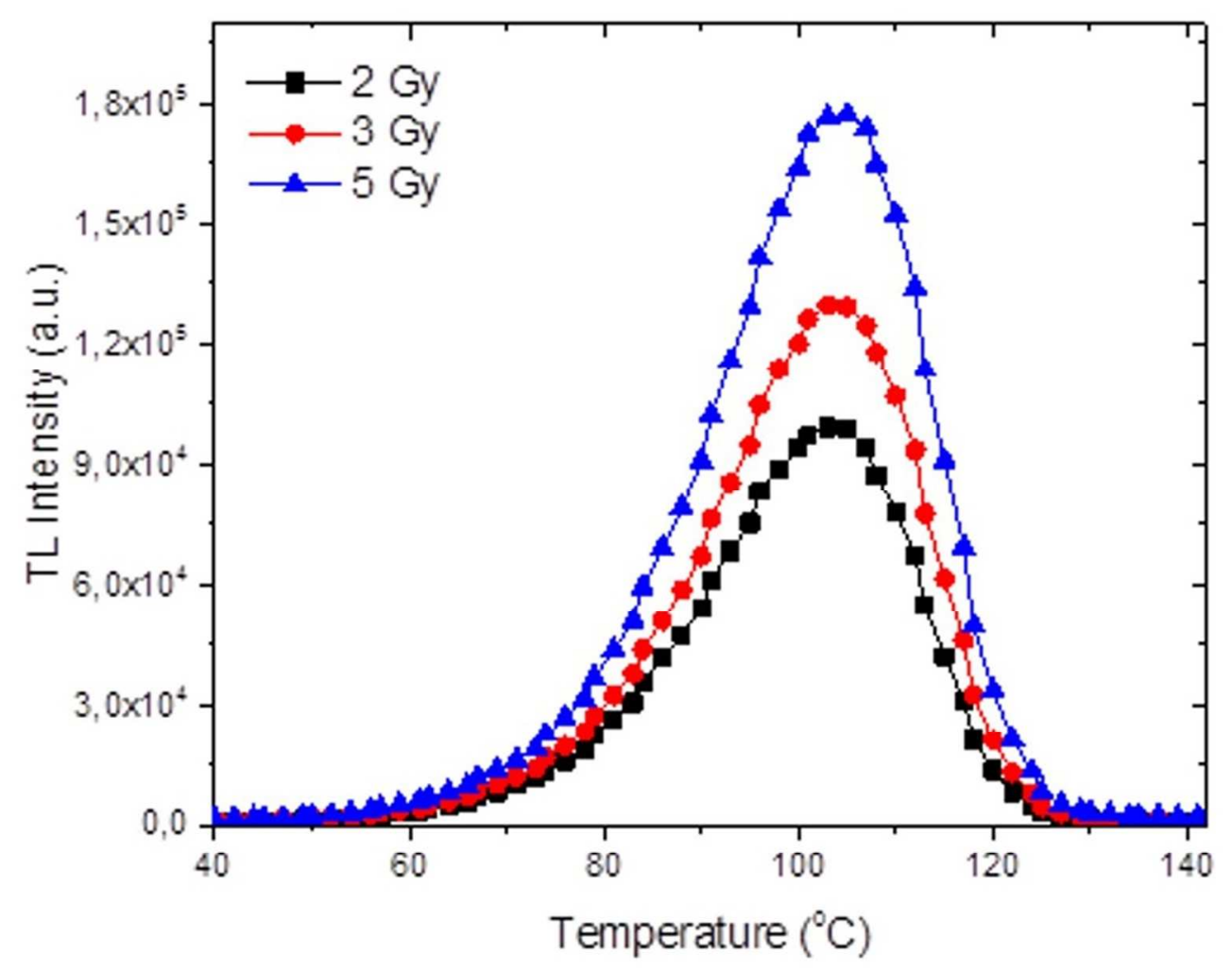

Figure 6. TL glow peaks of the quartz samples irradiated with test doses. $283 \times 222 \mathrm{~mm}(96 \times 96$ DPI $)$ 


\section{Tables}

Table 1. TL kinetic parameters obtained by CGCD, PS and ID methods for 2 Gy.

\begin{tabular}{cccc}
\hline Methods & $\mathbf{E}(\mathbf{e V})$ & $\left.\mathbf{s ~}^{-1}\right)$ & $\mathbf{b}$ \\
\hline CGCD & $1.01 \pm 0.04$ & $1.71 \times 10^{13}$ & 1 \\
PS & $0.98 \pm 0.05$ & $2.50 \times 10^{12}$ & 1 \\
ID & $1.11 \pm 0.06$ & $3.90 \times 10^{12}$ & 1 \\
\hline
\end{tabular}

